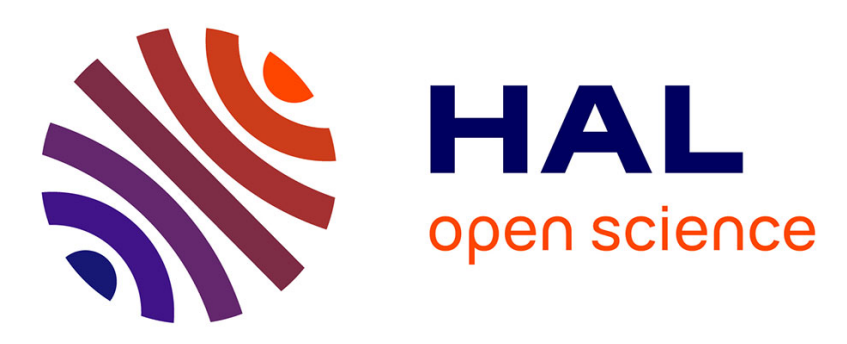

\title{
Thermomechanical and hygroelastic properties of an epoxy system under humid and cold-warm cycling conditions
}

Jalal El Yakoubi, Gilles Lubineau, Shahid Saghir, Jacques Verdu, Abe Askari

\section{- To cite this version:}

Jalal El Yakoubi, Gilles Lubineau, Shahid Saghir, Jacques Verdu, Abe Askari. Thermomechanical and hygroelastic properties of an epoxy system under humid and cold-warm cycling conditions. Polymer Degradation and Stability, 2014, 99 (1), pp.146-155. 10.1016/j.polymdegradstab.2013.11.011 . hal00980344

\section{HAL Id: hal-00980344 https://hal.science/hal-00980344}

Submitted on 1 Jun 2017

HAL is a multi-disciplinary open access archive for the deposit and dissemination of scientific research documents, whether they are published or not. The documents may come from teaching and research institutions in France or abroad, or from public or private research centers.
L'archive ouverte pluridisciplinaire HAL, est destinée au dépôt et à la diffusion de documents scientifiques de niveau recherche, publiés ou non, émanant des établissements d'enseignement et de recherche français ou étrangers, des laboratoires publics ou privés. 


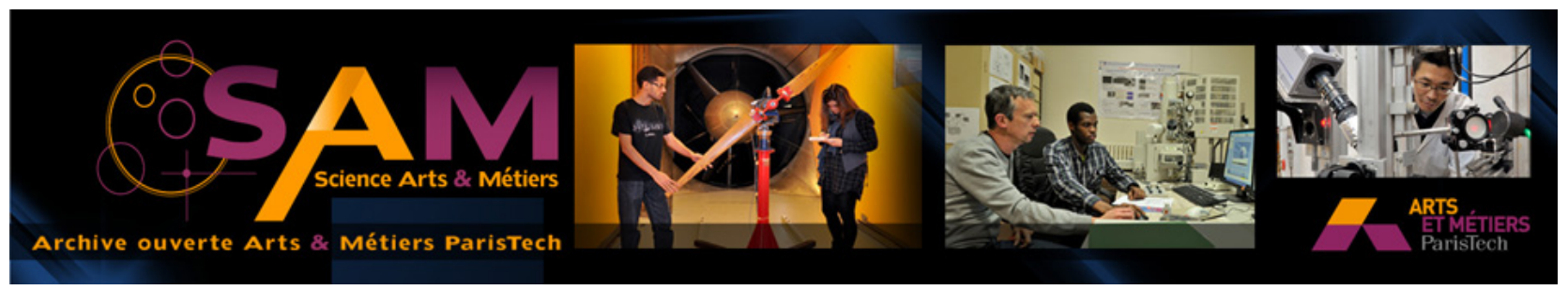

Science Arts \& Métiers (SAM)

is an open access repository that collects the work of Arts et Métiers ParisTech researchers and makes it freely available over the web where possible.

This is an author-deposited version published in: http://sam.ensam.eu Handle ID: .http://hdl.handle.net/10985/7976

\section{To cite this version :}

Jalal EL YAKOUBI, Gilles LUBINEAU, Shahid SAGHIR, Jacques VERDU, Abe ASKARI Thermomechanical and hygroelastic properties of an epoxy system under humid and cold-warm cycling conditions - Polymer Degradation and Stability - Vol. 99, n¹, p.146-155 - 2014 


\title{
Thermomechanical and hygroelastic properties of an epoxy system under humid and cold-warm cycling conditions
}

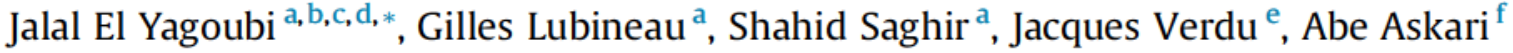 \\ ${ }^{a}$ King Abdullah University of Science and Technology (KAUST), Physical Science and Engineering Division, COHMAS Laboratory, Thuwal 23955-6900, \\ Saudi Arabia \\ b Univ. Bordeaux, I2M, UMR 5295, F-33400 Talence, France \\ ${ }^{c}$ CNRS, I2M, UMR 5295, F-33400 Talence, France \\ ${ }^{d}$ Arts et Metiers ParisTech, I2M, UMR 5295, F-33400 Talence, France \\ e Arts et Metiers ParisTech, Laboratoire PIMM, 151 Boulevard de l'Hopital, 75013 Paris, France \\ ${ }^{\mathrm{f}}$ The Boeing Company, Propulsion System Division, Everett, WA, USA
}

Keywords:

Epoxy

Hygrothermal aging

Hydrolysis

Sorption

\begin{abstract}
A B S T R A C T
In this paper, we study the hygrothermal aging of an anhydride-cured epoxy under temperature and hygrometry conditions simulating those experienced by an aircraft in wet tropical or subtropical regions. Gravimetric and dimensional measurements were performed and they indicate that there are three stages in this aging process: the first one, corresponding to the early cycles can be called the "induction stage". The second stage of about 1000 cycles duration, could be named the "swelling stage", during which the volume increase is almost equal to the volume of the (liquid) water absorbed. Both the first and second stages are accompanied by modifications of the mechanical properties and the glass transition temperature. During the third ("equilibrium") stage, up to 3000 cycles, there is no significant change in the physical properties despite the continuous increase of water uptake. This can be explained by the fact that only physically sorbed water can influence physical properties.
\end{abstract}

\section{Introduction}

Epoxy-based materials are utilized in many engineered structures, ranging from large civil infrastructures [1] to microelectronics [2] because they offer strong mechanical properties along with thermal and chemical stability. An important field of application is the one of carbone/epoxy composites that exhibit adaptability during the design [3] and high-level integration during the manufacturing process [4]. In particular, recent developments in the aeronautical industry have highlighted the important role of composite materials in improving aircraft design [5]. These composites have been introduced in primary components such as the fuselage. Under service conditions, such components are subjected to varied environmental conditions that can lead to material degradation [68]. Exposure to water vapor simultaneously with cyclic temperature changes is the predominant cause of degradation related to the outdoor environment. Although the phenomenology aging of the

\footnotetext{
* Corresponding author. King Abdullah University of Science and Technology (KAUST), Physical Science and Engineering Division, COHMAS Laboratory, Thuwal 23955-6900, Saudi Arabia. Tel.: +966 (0) 565560239.

E-mail address: jalal.elyagoubi@u-bordeaux1.fr (J. El Yagoubi).
}

laminated composites can appear to be very complex [6,7,9-11], a mandatory starting point is to understand the evolution of the properties of the constitutive resin. Many studies considered temperatures above $25^{\circ} \mathrm{C}$, but few addressed aging under representative cold $\left(-40^{\circ} \mathrm{C}\right)$ and warm $\left(70^{\circ} \mathrm{C}\right)$ conditions. An experimental analysis of the aging of bulk polymer is therefore required to identify the key mechanisms and provide the necessary database for the simulation of the whole aging process.

First of all, a general understanding of the phenomenology of aging is necessary. We review, in the following, the effects of the water penetration in the polymer, which can be divided into physical interactions and chemical effects.

\subsection{Physical interaction}

The first step in any hydrolytic aging process is the penetration of water into the organic matrix. Water is more or less soluble in epoxies, depending on the polar group content of the polymer, especially groups able to establish strong hydrogen bonds with water molecules. Experimental evidence of such hydrogen bonds, on the basis of NMR [12,13], from structure-solubility relationships [14] or from the analysis of the heat of dissolution [15] is extensive. 
The first important point is that the predominant part of the absorbed water molecules is effectively dissolved in the matrix (i.e., form a single phase with the polymer). The glass transition temperature $\left(T_{\mathrm{g}}\right)$ of such a mixture is expected to be between the glass transition temperature of the dry polymer $\left(T_{\mathrm{gd}}\right)$ and the one of water $\left(T_{\mathrm{gw}}\right)$. This latter temperature $(\sim 120 \mathrm{~K})$ is considerably lower than that of the epoxy (generally $>300 \mathrm{~K}$ ). As a result, water penetration induces a noticeable depression in the $T_{\mathrm{g}}$ of hydrophilic epoxies, a phenomenon called "plasticization". According to the free volume theory, the free volumes of both polymer and water are additive [16]. Using many simplifying hypotheses, this theory leads to the following relationship $[17,18]$ :

$\frac{1}{T_{\mathrm{g}}}=\frac{1}{T_{\mathrm{gd}}}+A_{\mathrm{pl}} m_{\mathrm{w}}$

where $m_{\mathrm{w}}$ is the mass fraction of the water in the mixture and $A_{\mathrm{pl}}$ is a so-called "plasticization coefficient", which can be expressed, in the simplest case, by:

$A_{\mathrm{pl}}=\frac{1}{T_{\mathrm{gw}}}-\frac{1}{T_{\mathrm{gd}}}$

$A_{\mathrm{pl}}$ ranges from about $5.5 \times 10^{-3} \mathrm{~K}^{-1}$ for $T_{\mathrm{gd}}=80{ }^{\circ} \mathrm{C}$ to about $6.5 \times 10^{-3} \mathrm{~K}^{-1}$ for $T_{\mathrm{gd}}=270{ }^{\circ} \mathrm{C}$. These relationships lead to:

$\frac{\mathrm{d} T_{\mathrm{g}}}{\mathrm{d} m_{\mathrm{w}}}=-A_{\mathrm{pl}} T_{\mathrm{g}}^{2}$

thus, $\mathrm{d} T_{\mathrm{g}} / \mathrm{d} m_{\mathrm{w}}$ ranges between $685 \mathrm{~K}$ for $T_{\mathrm{gd}}=80^{\circ} \mathrm{C}$ to $1770 \mathrm{~K}$ for $T_{\mathrm{gd}}=270^{\circ} \mathrm{C}$. This leads to a $T_{\mathrm{g}}$ depression per percent (mass) of absorbed water that ranges from about $7 \mathrm{~K}$ for $T_{\mathrm{gd}}=80^{\circ} \mathrm{C}$ to about $18 \mathrm{~K}$ for $T_{\mathrm{gd}}=270^{\circ} \mathrm{C}$.

Analysis of NMR $[13,19]$ or dielectric spectra [20,21] reveals, however, the coexistence of hydrogen-bonded and free water molecules. These latter could be present in clusters; in this case, they would not participate in polymer/water interactions. The knowledge of the total mass fraction of the water in the polymer might therefore not be sufficient to characterize the system.

Another important consequence of water dissolution in polymer matrices is swelling. A simple expression of volumetric effects resulting from water dissolution in a polymer is:

$V=V_{\mathrm{p}}+V_{\mathrm{L}}+\chi V_{\mathrm{p}} V_{\mathrm{L}}$

where $V_{\mathrm{p}}$ and $V_{\mathrm{L}}$ are the respective volumes of the polymer and liquid and $\chi$ is a so-called "interaction coefficient". In the case of water, $\chi$ is negative. In other words, water penetration in the polymer is accompanied by a contraction of the mixture but this contraction is not strong enough to inhibit the swelling totally [22]. This means that $0>\chi>-V_{\mathrm{P}}^{-1}$.

In the transient regime of diffusion where water concentration gradients exist across the sample's thickness, differential swelling induces a stress state [23-25]. Schematically, absorption induces compressive stresses in the superficial layers while desorption induces tensile stresses. These self-equilibrated stress states can be severe enough to introduce micro-damage, which can, in turn, modify the water sorption characteristics.

For a wide family of amine-cured epoxy networks (with complete curing), there is no possibility of chemical reactions with the water and the only possible degradation process is damage by swelling stresses in the transient diffusion regime.

\subsection{Chemical reaction}

Amine-cured epoxies that contain an excess of epoxy groups and anhydride-cured epoxies contain hydrolyzable groups (epoxy, ester, anhydride). In these cases, chemical polymer-water interactions complicate the aging behavior.

In the presence of unreacted epoxy or anhydride groups, hydrolysis can modify the diffusion behavior, which can turn from a Fick to a Langmuir process $[26,27]$. This has no direct effects on the polymer's mechanical behavior because hydrolysis does not affect the crosslink density.

In contrast, ester hydrolysis, in polyesters or in anhydride-cured epoxies, induces chain scission. This results in a decrease in the crosslink density and network embrittlement. Also, chain scission generates small molecular fragments and can induce osmotic cracking $[28,29]$.

Coupling of physico-chemical aging processes with mechanical loading is, then, a key objective and has inspired a relatively abundant literature [9-11,30]. As far as hydrolysis is concerned, reaction-diffusion coupling must be taken into account. After the pioneering work of Golike and Lasoski in the early 1960s [31], there was, to our knowledge, no significant work on diffusion-controlled hydrolysis during the last half century. Recently, our group published a study proposing a new formulation for reaction-diffusion coupling kinetics and its application to hygrothermal aging of anhydride-epoxy matrices [27].

It is worth noting that a similar framework exists for the oxidation of epoxy networks containing aliphatic structures. Literature reviews have been published $[32,33]$ on this topic. Oxygen reacts with these groups, at relatively high temperatures, and this contributes to material aging via network degradation [34] and via shrinkage induced oxidation [6,35].

Here, we study the behavior of an anhydride-cured epoxy under non-steady conditions similar to those of aeronautic flight conditions. We consider two extreme climates, one simulating the ceiling flight, characterized by low temperature $\left(-40^{\circ} \mathrm{C}\right)$, and the other simulating ground storage in a warm $\left(70^{\circ} \mathrm{C}\right)$, wet $(90 \% \mathrm{RH})$ environment. In the following section, we describe the material and we detail the experimental procedures used to monitor the polymer's behavior. Then, experimental results are reported for mass uptake, the changes in the glass transition temperature and the thermomechanical and hygroelastic properties. Finally, we highlight the sorption mechanisms and the relationships with the evolution of the polymer's properties.

\section{Experimental}

\subsection{Material and samples}

The material used in this study was a commercial epoxy resin (EPOLAM 2063, Axson Technology) based on a mixture of diglycidyl ether of bisphenol A (DGEBA) with a cycloaliphatic epoxide hardened by nadic methyl anhydride (also from Axson Technology). Both components were liquid. They were mixed and stirred at $80^{\circ} \mathrm{C}$ for $15 \mathrm{~min}$. The mixture was then cast in an aluminum mold to prepare $1 \mathrm{~mm}$ thick plates. The plates were then cured for $6 \mathrm{~h}$ at $80^{\circ} \mathrm{C}$ and post-cured for $6 \mathrm{~h}$ at $180^{\circ} \mathrm{C}$ to obtain as complete conversion of the epoxide-anhydride reaction as possible.

Neat polymer samples were cut using a diamond saw. The samples were conditioned in a dessicator at room temperature prior to aging.

\subsection{Exposure conditions}

Specimens for aging were placed inside an environmental chamber where both temperature and relative humidity were 
controlled to $\pm 0.3{ }^{\circ} \mathrm{C}$ and $\pm 2 \% \mathrm{RH}$, respectively. Fig. 1 shows the arrangement of the samples inside the chamber. They were inclined to avoid stagnation of the condensed water on their surface. The system was designed to ensure good ventilation of the whole chamber volume. Thermocouples (type T-316SS12-U-T4) were used to monitor the temperature at each rack as the temperature may have varied inside the climatic chamber. The maximum variation in the temperature was about $15^{\circ} \mathrm{C}$ when the programmed temperature reached $70^{\circ} \mathrm{C}$.

Cycling was preceded by a holding stage of $12 \mathrm{~h}$ at $70{ }^{\circ} \mathrm{C}$ and $90 \%$ $\mathrm{RH}$. This stage was immediately followed by the cycling as schematized in Fig. 2. High humidity (90\% RH) was maintained during the portion of the cycle in which the temperature exceeded $55^{\circ} \mathrm{C}$. It remained higher than $70 \% \mathrm{RH}$ at temperatures above $25^{\circ} \mathrm{C}$. It was almost zero during the low temperature part of the cycle. It should be noted that, for temperatures below $25^{\circ} \mathrm{C}$, and particularly for negative temperatures $\left(<0^{\circ} \mathrm{C}\right)$, the diffusion and reaction processes are significantly slower than they are during the hot stage. The temperature ramps were $2 \mathrm{~K} / \mathrm{min}$ for cooling and $5 \mathrm{~K} / \mathrm{min}$ for heating. Exposures up to 3000 cycles were run.

To monitor the polymer degradation, samples were tested at pre-defined numbers of cycles between 0 and 3000 . The specimens were tested at a high frequency up to 500 cycles, because we expected rapid changes in the polymer's properties. Then, experimental data were collected at a lower frequency until the end of the campaign (i.e., 3000 cycles). As depicted in Fig. 2, samples were collected during the cooling phase when the temperature approached $25{ }^{\circ} \mathrm{C}$. Certain samples, unaltered by characterization methods, were reintroduced in the chamber, also during the cooling phase at $25^{\circ} \mathrm{C}$. In the following section, each experimental method is described.

\subsection{Characterization}

\subsubsection{Gravimetric and volumetric properties}

Two identical specimens of $60 \times 40 \times 1 \mathrm{~mm}^{3}$ were frequently taken out from the chamber for gravimetric and density measurements. After being tested, these samples were returned to the chamber.

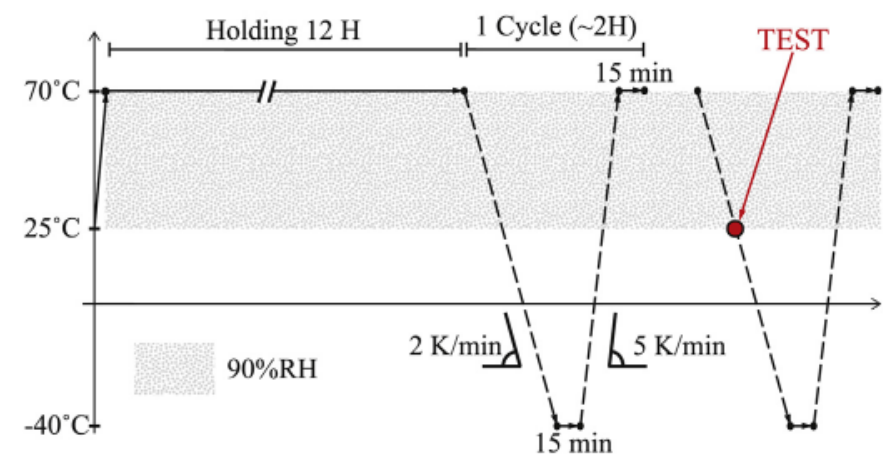

Fig. 2. Schematic representation of the hygrothermal cycling utilized for accelerated aging.

An analytical balance (Ohaus DV214CD, precision of $0.1 \mathrm{mg}$ ) along with an integrated density kit were used to monitor the mass and the volume changes during the entire aging period. The aged specimens were removed from the chamber, carefully wiped and immediately tested. Experiments were conducted at the ambient temperature $\left(22.5 \pm 0.5^{\circ} \mathrm{C}\right)$. The measurement procedure consisted of the following steps:

- First, specimens were weighed to monitor the evolution of the global mass uptake $\left(m_{\mathrm{w}}\right)$, which is derived from the sample mass $\left(m_{\mathrm{s}}\right)$ according to Eq. (5):

$m_{\mathrm{w}}(N)=\frac{m_{\mathrm{s}}(N)-m_{\mathrm{s}}^{0}}{m_{\mathrm{s}}^{0}}$

where $m_{\mathrm{s}}^{0}$ is the initial mass of the sample and $N$ is the number of cycles.

- Second, the polymer's density was measured using Archimede's method. Specimens were weighed in a pan that was immersed in distilled water. The specimen's density $\left(\rho_{s}\right)$ was then calculated according to Eq. (6):

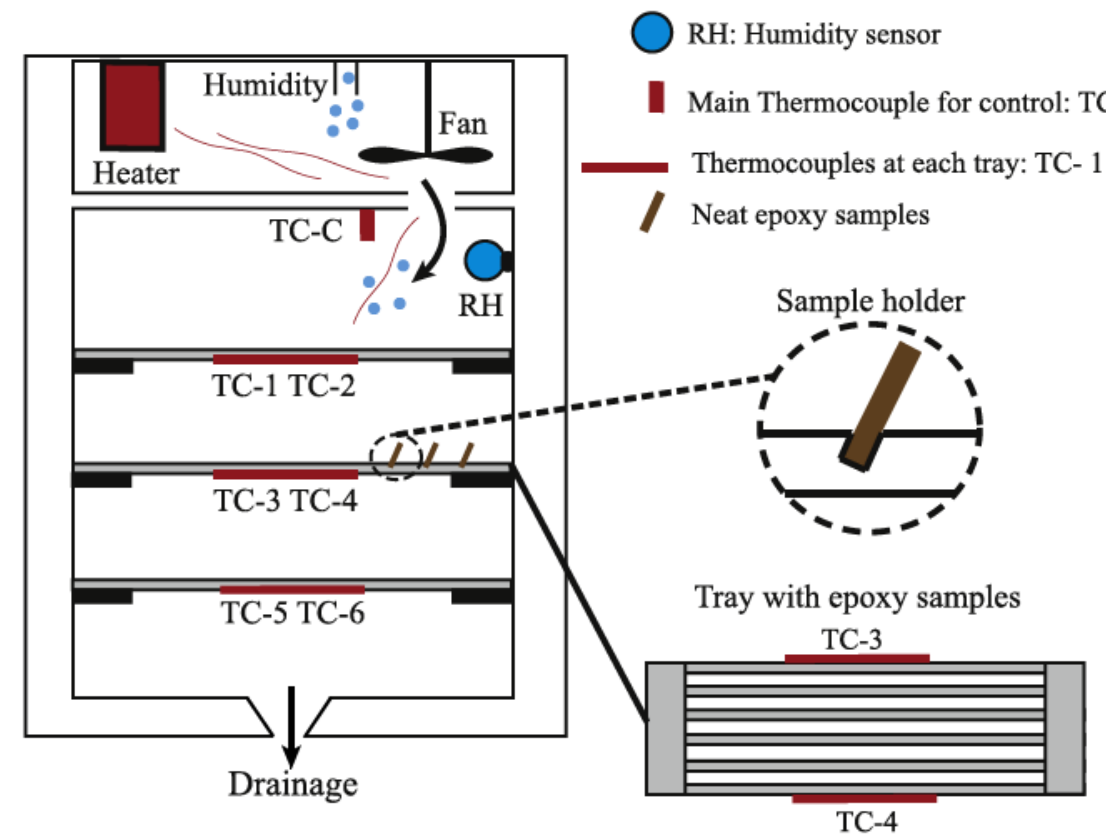

Fig. 1. Schematic representation of the environmental chamber where samples were placed and exposed to cyclic hygrothermal aging. 
$\rho_{\mathrm{s}}(N)=\rho_{\mathrm{d}} \times\left(\frac{m_{\mathrm{s}}(N)}{m_{\mathrm{s}}(N)-m_{\mathrm{i}}(N)}\right)$

where $\rho_{\mathrm{d}}$ was the density of the distilled water and $m_{\mathrm{i}}$ is the resulting reading of the mass when the sample is immersed in water. The relative variation of the polymer's density, denoted as $\rho_{\mathrm{w}}$, is defined as follows (Eq. (7)):

$\rho_{\mathrm{w}}(N)=\frac{\rho_{\mathrm{s}}(N)-\rho_{0}}{\rho_{0}}$

The volume change $\left(V_{\mathrm{w}}\right)$ is then derived from the mass uptake and the density change according to the following expression (Eq. (8)):

$V_{\mathrm{w}}(N)=\frac{V_{\mathrm{s}}(N)-V_{0}}{V_{0}}$

where $V_{\mathrm{s}}$ is the volume of the aged samples and $V_{0}$ is the initial volume of the specimens.

\subsubsection{Mechanical testing}

First, tensile tests were performed on the epoxy samples that were not submitted to environmental conditions to determine the initial tensile properties (Young's modulus, Poisson's ratio). The tests were conducted on an INSTRON machine under a constant extension rate of $2 \mathrm{~mm} / \mathrm{min}$. The dog-bone-shaped specimens were prepared as per the ASTM standard D 638-03. The respective initial tensile modulus, Poisson's ratio, stress to failure and strain to failure were: $3.1 \mathrm{GPa} ; 0.3 ; 50 \pm 5 \mathrm{Mpa} ; 2 \pm 0.15 \%$, respectively.

Second, monitoring of the degradation of the mechanical properties during aging was achieved by instrumented indentation tests (microindentation, Nanovea company). Specimens of $40 \times 40 \times 1 \mathrm{~mm}^{3}$ were removed from the chamber and carefully wiped. Then, the polymer plates were glued on top of a $10 \mathrm{~mm}$ thick stainless-steel substrate. The time that elapsed before the indentation test was started was less than 15 min. The tests were performed on nine locations of the samples following a $3 \times 3$ array with $0.5 \mathrm{~mm}$ spacing. We used an indentor with a $200 \mu \mathrm{m}$ diameter spherical tip (diamond). The experiments were performed at a constant load rate $(2 \mathrm{~N} / \mathrm{min})$ during loading and unloading. After reaching the maximum level of $4 \mathrm{~N}$, the load was maintained for $15 \mathrm{~s}$ and the creep displacement was recorded.

The load-displacement curves were analyzed to estimate the elastic modulus and the hardness of the material (ASTM standard E2546). First, the reduced modulus $\left(E_{\mathrm{r}}\right)$ was derived from Eq. (9):

$E_{\mathrm{r}}(N)=\frac{\sqrt{\pi}}{2} \frac{S_{\mathrm{c}}(N)}{\sqrt{A_{\mathrm{p}}(N)}}$

where $S_{\mathrm{c}}$ is the contact stiffness calculated from the unloading curve and $A_{\mathrm{p}}$ is the projected contact area. The indentation modulus $\left(E_{\Gamma \mathrm{T}}\right)$ and the hardness $\left(H_{\Pi \mathrm{T}}\right)$ were then computed following Eq. (10) and Eq. (11):

$$
\begin{aligned}
& E_{\mathrm{IT}}(N)=\left(1-v_{\mathrm{s}}^{2}\right)\left[\frac{1}{E_{\mathrm{r}}(N)}-\frac{\left(1-v_{\mathrm{i}}^{2}\right)}{E_{\mathrm{i}}}\right]^{-1} \\
& H_{\mathrm{IT}}(N)=\frac{F_{\max }}{A_{\mathrm{p}}(N)}
\end{aligned}
$$

where $\nu_{\mathrm{i}}$ and $\nu_{\mathrm{s}}$ are the Poisson's ratios of the indentor tip and the epoxy. As a first approximation, we assumed that $\nu_{\mathrm{s}}$ was not affected by the aging.

\subsubsection{Dynamic mechanical analysis}

Dynamic mechanical analysis (DMA) was conducted in the single cantilever mode at a frequency of $1 \mathrm{~Hz}$ (Netzch DMA242). DMA specimens were $10 \pm 0.07 \mathrm{~mm}$ in width, $1 \pm 0.03 \mathrm{~mm}$ in thickness and $35 \pm 0.2 \mathrm{~mm}$ in length. Viscoelastic properties were measured at temperatures ranging from $25{ }^{\circ} \mathrm{C}$ to $225{ }^{\circ} \mathrm{C}$ with a heating rate of $5 \mathrm{~K} / \mathrm{min}$. These tests were used to determine the glass transition temperature.

It is worth noting that the DMA tests were started about $15 \mathrm{~min}$ after the aged samples were taken out from the environmental chamber. In addition, we evaluated the amount of water that would be desorbed during a DMA experiment. For this purpose, we conducted thermogravimetric analysis under similar conditions as those for the DMA tests. We found that more than $90 \%$ of the sorbed water remained within the polymer when the temperature reached the glass transition temperature. This was a good indication that the glass transition temperature, derived from the DMA curves, was significant to the aging process.

\subsubsection{Strain measurement}

A data acquisition system (System 7000 from Vishay Company) was used to collect the strain and the temperature signals during hygrothermal cycling. For this purpose, two epoxy specimens were instrumented with strain gauges. The temperature in the vicinity of each sample was measured by thermocouples (TC-3 and TC-4). The reference temperature was $T_{0}=23^{\circ} \mathrm{C}$. Regularly, strains and temperatures were acquired during a period of two to three cycles. The dedicated samples were $15 \pm 0.5 \mathrm{~mm}$ in width, $1 \pm 0.03 \mathrm{~mm}$ in thickness and $65 \pm 0.5 \mathrm{~mm}$ in length.

\section{Results}

\subsection{Water uptake}

The evolution of the mass accounts for the overall amount of water sorbed by the polymer. We previously showed in Ref. [27] that the studied epoxy system displays non-Fickian behavior. The short-term isothermal sorption experiments revealed two stages in the mass uptake [27]. Fig. 3 shows that the mass uptake under hygrothermal cycling corroborates the results of the sorption experiments under isothermal conditions. In fact, the mass uptake did not stabilize even after 3000 cycles. We identified three stages:

- A rapid mass increase of about $1 \%$ was observed following the soak time ( $12 \mathrm{~h}$ at $70{ }^{\circ} \mathrm{C}$ and $\left.90 \% \mathrm{RH}\right)$.

- From the first cycle to 250 cycles, the mass uptake increased at a decreasing rate.

- After a transition at 250 cycles, the mass of the samples increased linearly with respect to the number of cycles.

\subsection{Dimensional changes}

During the hygrothermal cycling, both the temperature and the humidity contributed to the dimensional changes.

- The evolution of the total in-plane linear $(L)$ hygrothermal strain $\left(\varepsilon_{\mathrm{ht}}^{L}(T, N)\right)$ versus the temperature is plotted in Fig. 4. From a global viewpoint, this deformation can be partitionned into a thermal one $\left(\varepsilon_{\mathrm{t}}^{L}\right)$ and a hydric one $\left(\varepsilon_{\mathrm{h}}^{L}\right)$ that can be both a function of the temperature $(T)$ and the number of cycles $(N)$. Fig. 4 shows that the total in-plane strain evolves linearly with the temperature and the curves shift up with the number of cycles. As a first approximation, we can reasonably assume that the total strain could be partitioned as follows (Eq. (12)): 


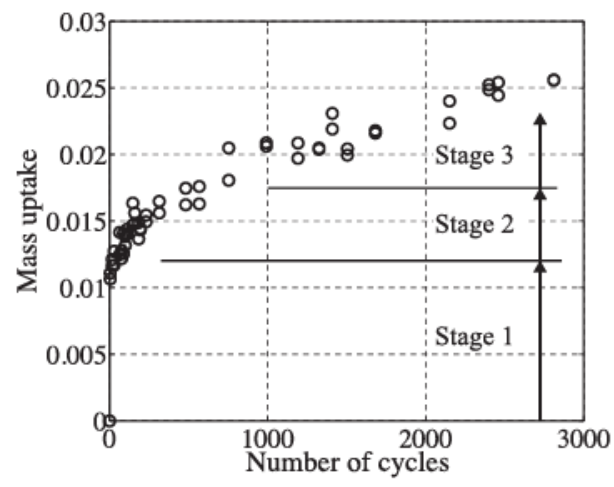

(a) up to 3000 cycles

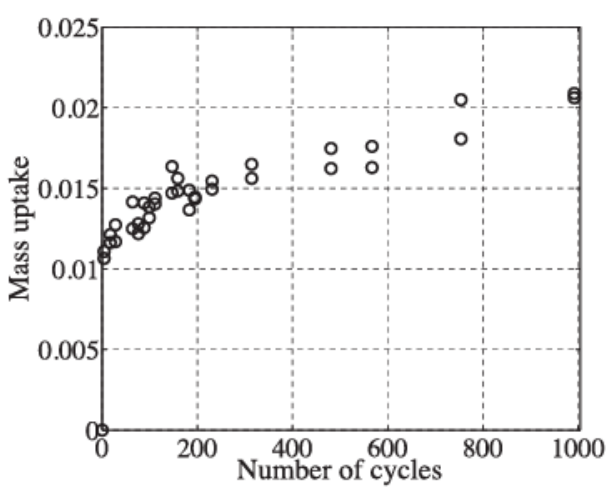

(b) up to 1000 cycles

Fig. 3. Mass uptake in relation to the number of cycles.

$\varepsilon_{\mathrm{ht}}^{L}(T, N)=\varepsilon_{\mathrm{t}}^{L}(T, N)+\varepsilon_{\mathrm{h}}^{L}(N)$

Therefore, we calculated the coefficient of thermal expansion (CTE, $\alpha$ ) as the derivative of the in-plane strain with respect to the temperature (Eq. (13)).

$\alpha(T, N)=\frac{\partial \varepsilon_{\mathrm{ht}}^{L}(T, N)}{\partial T}$

Interestingly, we found that the CTE did not experience any detectable change with the number of cycles. Also, it appears that the coefficient has a tendency to increase with the temperature. It ranges from $61 \times 10^{-6} \mathrm{C}^{-1}$ at $-30^{\circ} \mathrm{C}$ to $75 \times 10^{-6} \mathrm{C}^{-1}$ at $70^{\circ} \mathrm{C}$. Then, the hydric in-plane strain $\left(\varepsilon_{\mathrm{h}}^{L}\right)$ was obtained after subtracting the thermal strain from the total strain.

- We measured the evolution of the volume change at the ambient temperature $\left(V_{\mathrm{w}}\right)$ as a function of the number of cycles (Fig. 5). This only accounts for the moisture-induced swelling because it was measured at the reference temperature chosen for the thermal strain, $T_{0}$.

The variation in the volume also exhibits several stages:

- A rapid volume increase of about $0.5 \%$ was subsequent to the soak time $\left(12 \mathrm{~h}\right.$ at $70{ }^{\circ} \mathrm{C}$ and $\left.90 \% \mathrm{RH}\right)$.



Fig. 4. Total in-plane hygrothermal strain $\left(\varepsilon_{\mathrm{ht}}^{L}(T, N)\right)$ versus temperature.
- From the first cycle to 250 cycles, the material swelled linearly with the number of cycles.

- Between 250 cycles and 1000 cycles, the volume of the samples continued to increase linearly but at a rate that was reduced.

- Finally, after 1000 cycles, it appears that the volume remained mostly constant (about $1.5 \%$ ).

Assuming that the hygroelastic behavior was isotropic, we can estimate an equivalent hydric strain from the volume uptake according to Eq. (14). Fig. 6 shows that it is comparable to the in-plane strain, $\varepsilon_{\mathrm{h}}^{L}$ (measured using strain gauges).

$\varepsilon_{\mathrm{h}}^{V}(N)=\frac{V_{\mathrm{w}}}{3}$

\subsection{Glass transition temperature}

We evaluated the effect of aging on the glass transition temperature by means of DMA. The retained definition of the glass transition temperature $\left(T_{\mathrm{g}}\right)$ was based on the $\tan (\delta)$ peak. This peak revealed neither splitting nor significant broadening, supporting an efficient dissolution of water in the polymer.

The evolution of the glass transition temperature in relation to the number of cycles is shown in Fig. 7. The water uptake resulted in a decrease in the glass transition temperature. Contrary to the mass uptake and the volume change, the evolution of this quantity with the number of cycles was not monotonic. Fig. 7 reveals three stages:

- A rapid decrease was observed during the first 200 cycles.

- Then, $T_{\mathrm{g}}$ reincreased slowly between 250 cycles and 1000 cycles. This particular observation is in agreement with the results reported by Zhou and Lucas [13].

- Finally, $T_{\mathrm{g}}$ remained mostly constant until the end of the aging campaign.

\subsection{Mechanical properties}

The effect of aging on the polymer's mechanical behavior was monitored by means of instrumented indentation tests. The initial value of the indentation modulus ( $3.02 \mathrm{GPa}$ ) was very close to the tensile modulus obtained on dog-bone-shaped samples (3.1 GPa). Fig. 8 shows the modulus changes, which were clearly correlated to $T_{\mathrm{g}}$ changes. It can be reasonably supposed that both evolutions resulted from the same processes.

Variation in the hardness is shown in relation to the number of cycles in Fig. 9. Similarly to the $T_{\mathrm{g}}$ and the modulus, the hardness 




(a) up to 3000 cycles

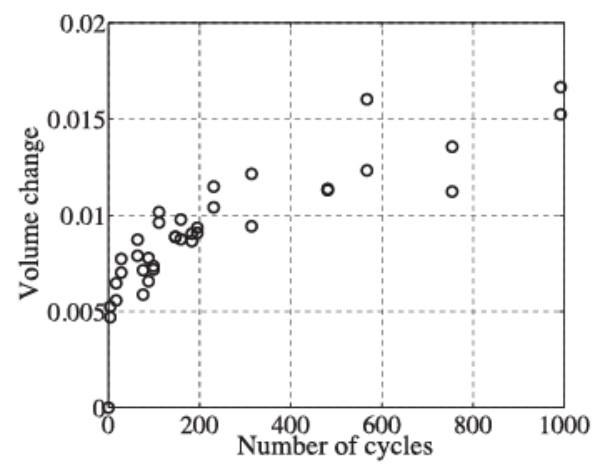

(b) up to 1000 cycles

Fig. 5. Relative volume change in relation to the number of cycles.

decreased rapidly during the first stage of water uptake. A slow increase can be surmised in the second stage, but it was partly masked by the scatter. The variation in the maximum creep displacement after $15 \mathrm{~s}$ is shown in Fig. 10. Similarly to the other properties, it varies (increases) rapidly during the first stage but remains almost constant during the rest of aging campaign.

\section{Discussion}

In the previous section, we reported experimental results on the sorption kinetics, the thermomechanical and hygroelastic behaviors, and the glass transition temperature. In the following, we propose a degradation scenario that is consistent with the abovementioned results.

\subsection{Sorption mechanisms and kinetics}

Let us first consider the mass uptake kinetics (Fig. 3). The absence of equilibrium suggests the existence of a chemical reaction in which water molecules are incorporated in the polymer structure, i.e. a hydrolysis phenomenon. At low conversions, hydrolysis behaves as a zero-order process, i.e., at an almost constant rate, which explains the linear shape of the curve in its second

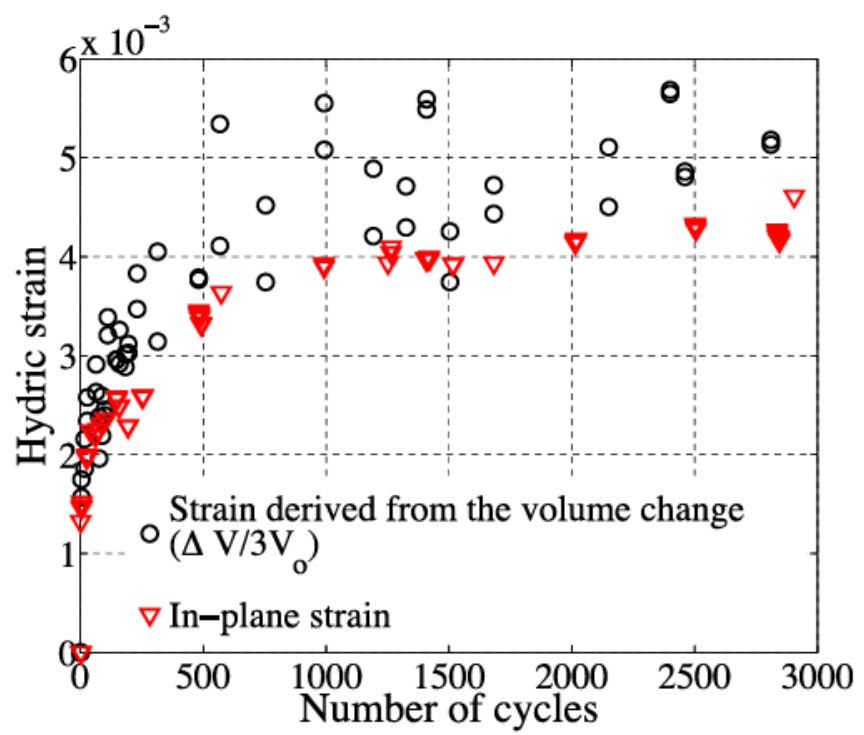

Fig. 6. Comparison between the in-plane hydric strain and the global strain derived from the volume change assuming isotropic hygroelastic behavior. stage. As a first approximation, the whole mass uptake, $m_{\mathrm{w}}$, can be divided into two parts $\left(m_{\mathrm{w}}=m_{\mathrm{w}}^{1}+m_{\mathrm{w}}^{2}\right)$. The water uptake, $m_{\mathrm{w}}^{2}$, during the second stage, which accounts for the hydrolysis reaction and the hydrophylicity increase [27], can be approximated by the following equation:

$m_{\mathrm{w}}^{2}=4.17 \times 10^{-6} \mathrm{~N}$

By subtracting $m_{\mathrm{w}}^{2}$ from the whole mass uptake, $m_{\mathrm{w}}$, we obtain a curve, $m_{\mathrm{w}}^{1}=m_{\mathrm{w}}-m_{\mathrm{w}}^{2}=f(N)$, with an horizontal asymptote of which the ordinate $\left(m_{w}^{1 s}=0.0175\right)$ would correspond to the initial equilibrium concentration of the physically sorbed water. The first stage thus corresponds to the physical absorption of water. The kinetics presumably obey Fick's law but this is difficult to confirm owing to the lack of data in the early period of exposure for mass uptake values lower than $60 \%$ of the equilibrium value. Nevertheless, Fickian behavior was confirmed by the results of gravimetric experiments reported in a previous paper [27] on the same material.

Diffusion and reaction processes occur at different time scales, which we discuss in the following by considering the characteristic time of the temperature variations.

According to our previous work, the coefficient of diffusion of water at $50{ }^{\circ} \mathrm{C}$ is $5 \times 10^{-12} \mathrm{~m}^{2} \mathrm{~s}^{-1}$. The characteristic time of diffusion, $t_{\mathrm{D}}\left(h^{2} / D\right)$, for samples of $1 \mathrm{~mm}$ thickness $(2 h)$ would be of the order of a few tens of hours at $70^{\circ} \mathrm{C}$. It would be 6-20 times longer at ambient temperature depending on the activation energy of diffusion (presumably $30-50 \mathrm{~kJ} / \mathrm{mol}$ ). These data suggest that most of the water uptake results from water absorption during the initial holding stage which is presumably not very different from the characteristic time of diffusion. In contrast, this is significantly longer than the characteristic time, $t_{\mathrm{c}}$ (Eq. (16)), of cooling, which is defined as:

$t_{\mathrm{c}}=\left(\frac{1 \mathrm{~d} T}{T} \frac{-1}{\mathrm{~d} t}\right)^{-1}$

At $70{ }^{\circ} \mathrm{C}$, the $t_{\mathrm{c}}$ is of the order of $10^{3} \mathrm{~s}$ compared with $10^{5} \mathrm{~s}$ for diffusion. It thus appears that temperature changes are presumably too fast to induce important changes in the water concentration. Indeed, the difference between $t_{\mathrm{D}}$ and $t_{\mathrm{c}}$ increases when the temperature decreases. In other words, we can suppose that most of the water transport occurs in the hot/wet stage of the cycle. The water distribution in the sample thickness is rapidly "frozen" when the temperature begins to decrease.

Eq. (15) suggests interesting supplementary information. The mass uptake in the second stage is $4.17 .10^{-6} \mathrm{~g}$ of water per initial gram of polymer per cycle. This quantity corresponds to about 


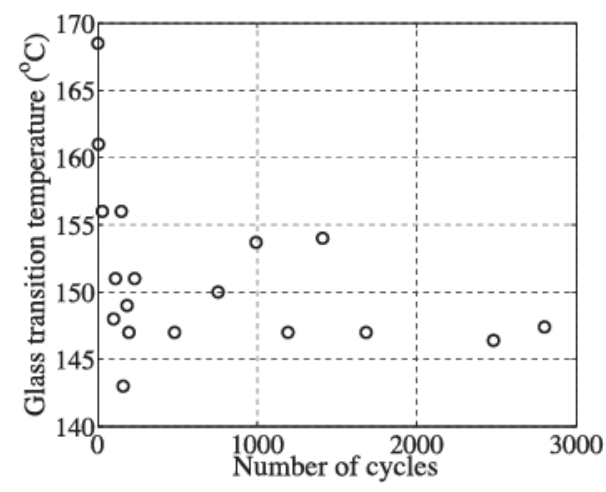

(a) up to 3000 cycles

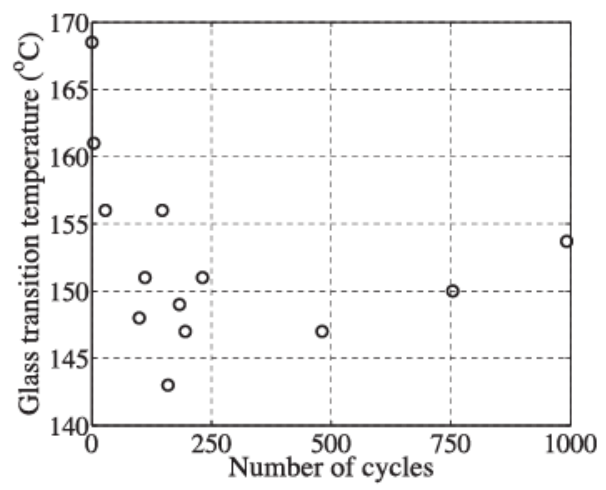

(b) up to 1000 cycles

Fig. 7. Variation of the glass transition temperature in relation to the number of cycles.

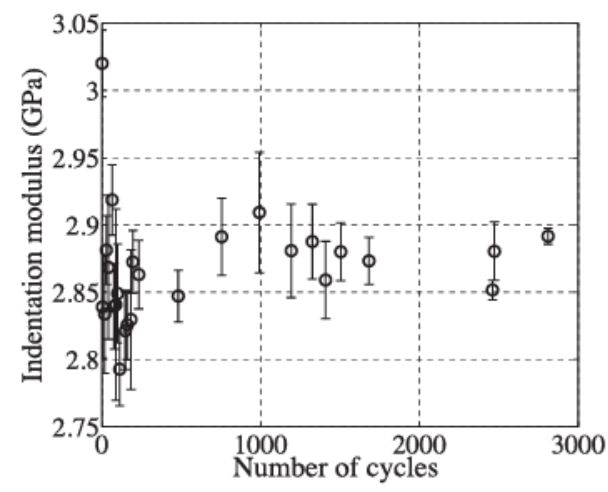

(a) up to 3000 cycles

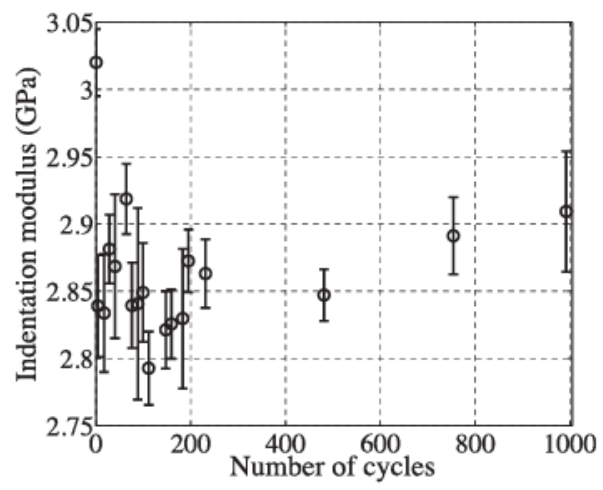

(b) up to 1000 cycles

Fig. 8. The indentation modulus in relation to the number of cycles.

$2.8 .10^{-4} \mathrm{~mol} / \mathrm{L}$. cycle. According to [27], the water solubility increase contributes about a third to the mass uptake measured in the second stage at $50{ }^{\circ} \mathrm{C}$. The actual duration, $t_{\mathrm{H}}$, of the hot/wet plateau of the cycle is $15 \mathrm{~min} \pm 5 \mathrm{~min}$. Assuming that most of the hydrolysis events occur during this plateau and that only $2 / 3$ of the mass increase results from hydrolysis, we estimate the hydrolysis rate, $r$ :

$r=\frac{2}{3} \times \frac{2.8 \times 10^{-4}}{t_{\mathrm{H}}} \sim 2.1 \times 10^{-7} \mathrm{~mol} . \mathrm{L}^{-1} \mathrm{~s}^{-1}$

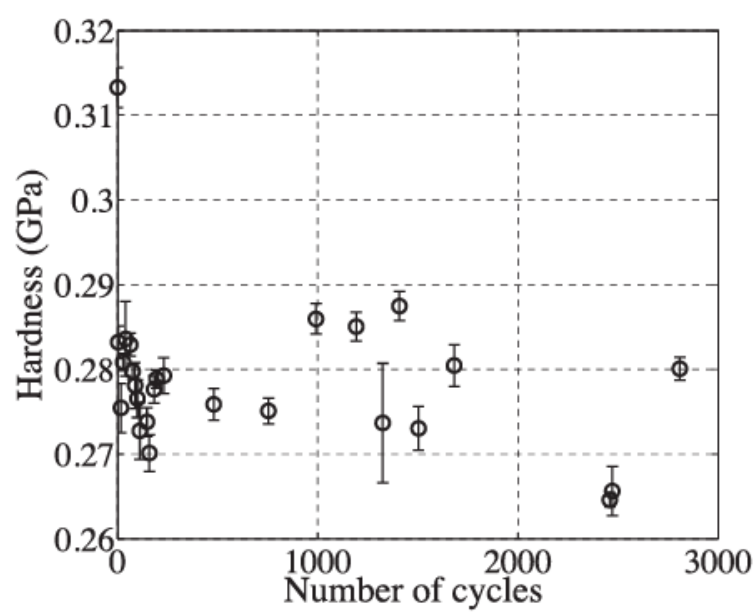

Fig. 9. Hardness in relation to the number of cycles.
This value is slightly high compared, for instance, with that for unsaturated polyester $(2-15) \times 10^{-7} \mathrm{~mol} . \mathrm{L}^{-1} \mathrm{~s}^{-1}$ at $100{ }^{\circ} \mathrm{C}$ and approximately 7 times lower at $70^{\circ} \mathrm{C}$ (with an activation energy of about $70 \mathrm{~kJ} / \mathrm{mol}[36]$ ). This means that the species undergoing hydrolysis is more reactive with water than is a common aliphatic or aromatic ester.

Finally, property changes can be interpreted, at least at first glance, on the basis of the following simple scenario: the first stage, of a duration presumably shorter than 200 cycles, is dominated by

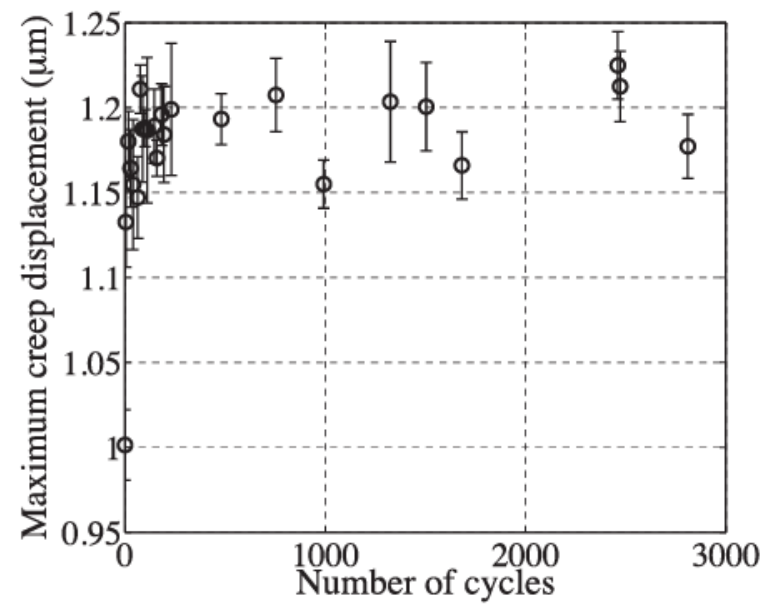

Fig. 10. Maximum creep displacement during the indentation test in relation to the number of cycles. 
the physical sorption of water. During this stage, the total water concentration in the polymer increases, hydrolysis begins but its conversion remains low and its effects on properties are negligible. The main physical processes affecting polymer properties are plasticization and swelling. At the end of the first stage, sorption has reached its equilibrium and the total water concentration will undergo changes linked, for instance, to the build-up of highly hydrophilic groups (alcohols and acids) resulting from hydrolysis.

\subsection{Plasticization}

Considering that the equilibrium $T_{\mathrm{g}}$ value is $147^{\circ} \mathrm{C}$ and the mass uptake at equilibrium is $1.75 \%$, the $T_{\mathrm{g}}$ depression per percent is: $\Delta T_{\mathrm{g}} / \Delta m \sim 12.6 \mathrm{~K} / \%$. This value is about double the theoretical value ( $7 \mathrm{~K} /$ percent) according to Eq. (3). This is not surprising, given that water is a peculiar solvent because its miscibility with other substances is mainly governed by the possibility of establishing very strong secondary (hydrogen) bonds with the polar groups of the partner. What we see here is that water seems to be a more efficient plasticizer than would be a non-polar or moderately polar solvent having the same $T_{\mathrm{g}}$.

If $T_{\mathrm{g}}=f(N)$ effectively displays a secondary maximum during the second stage, we can reject the hypothesis of secondary crosslinking proposed by Zhou and Lucas [13] in a similar case because of the occurrence of "decrosslinking". The decrease after 1000 cycles would be extremely difficult to justify. It seems to us better to envisage an effect of the swelling process occurring in this stage.

\subsection{Mechanical properties}

Fig. 11a shows that the indentation modulus is not correlated with the mass uptake. Indeed, after 250 cycles, the mass of the sample continues to increase while the modulus slightly recovers. On the contrary, Fig. 11b points out a remarkable correlation between the glass transition temperature and the elastic modulus. It can be reasonably postulated that both evolutions result from the same processes.

The rapid modulus decrease during the first stage (Fig. 8) is usually interpreted in terms of plasticization but this is not obvious. As a matter of fact, in several cases, as well in linear polymers as in epoxy networks, plasticization is accompanied by a modulus increase in the temperature interval between the first sub-glass transition $\left(T_{\beta}\right)$ and $T_{\mathrm{g}}$ [37]. This phenomenon, called antiplasticization, could however be specific to polymers displaying an intense dissipation band at $\left(T_{\beta}\right)$, which is not the case for anhydride-cured epoxies and more generally tridimensional polyesters. It is difficult to interpret this small (maximum 7\%) change in terms of material structural changes only, because during this period, the water is not homogeneously distributed across the sample thickness, which generates a stress state and can modify the material's mechanical response.

About half of the initial decrease is recovered during the second stage. Here also, it seems reasonable to establish a relationship between this phenomenon and the swelling that occurs during this stage. It should be noted that the evolution of the modulus is another element to reject the hypothesis of secondary crosslinking [13] because it would not be sensitive to crosslinking at room temperature. It is tempting to suppose that all the changes that occur between about 250 and 1000 cycles are linked to transient processes and that this value of $5 \%$ corresponds to an equilibrium state corresponding to an equilibrium concentration (1.75\%) of physically sorbed water. During the third stage (beyond $1000 \mathrm{cy}-$ cles), the modulus remains almost constant, differing from the initial value by about $(5 \pm 0.6) \%$.

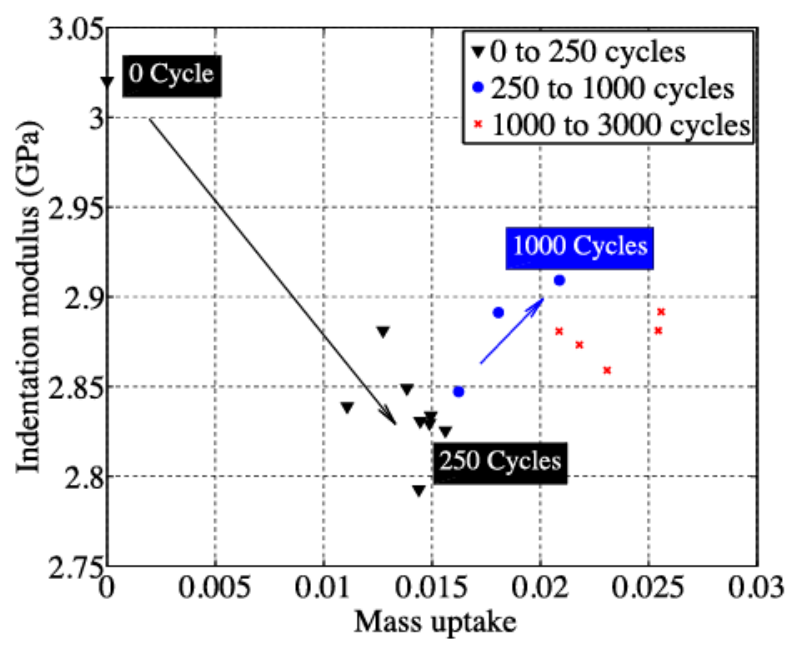

(a)

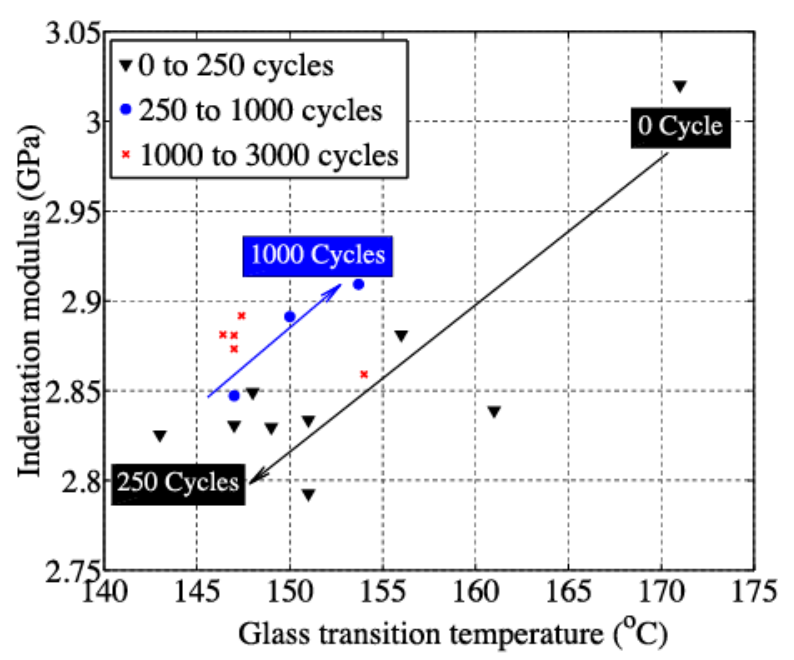

(b)

Fig. 11. The empirical relationship between the indentation modulus and (a) the mass uptake and (b) the glass transition temperature.

In addition, the hardness is relatively well correlated to the modulus: $H \sim E / 10$. The maximum creep displacement during the indentation test is more sensitive than the modulus or the hardness because it increases by about $20 \%$ during the first stage. Then, it remains almost constant for the remainder of the aging campaign.

\subsection{Volumetric properties}

The curve of volume change (Fig. 5) has the same shape as the mass uptake one, at least until 1000 cycles. The volume increases rapidly in the first stage at a continuously decreasing rate. It continues to increase in the second stage at a reduced but almost constant rate. During the first stage, water penetration in the sample is accompanied by a contraction because the volume increase is smaller than the volume of (liquid) water absorbed (Fig. 12).

The curve in Fig. 12 and the evolution of density (Fig. 13) can be schematized into a three-stage process. During the first stage, which corresponds to the first cycles, swelling is low. This type of behavior has been observed in several polymers among which are 


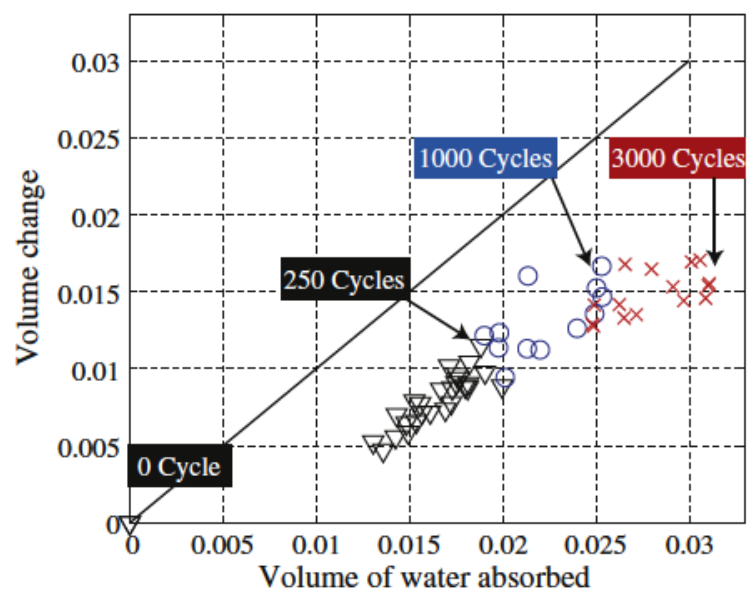

Fig. 12. The volume change in relation to the volume of (liquid) water absorbed.

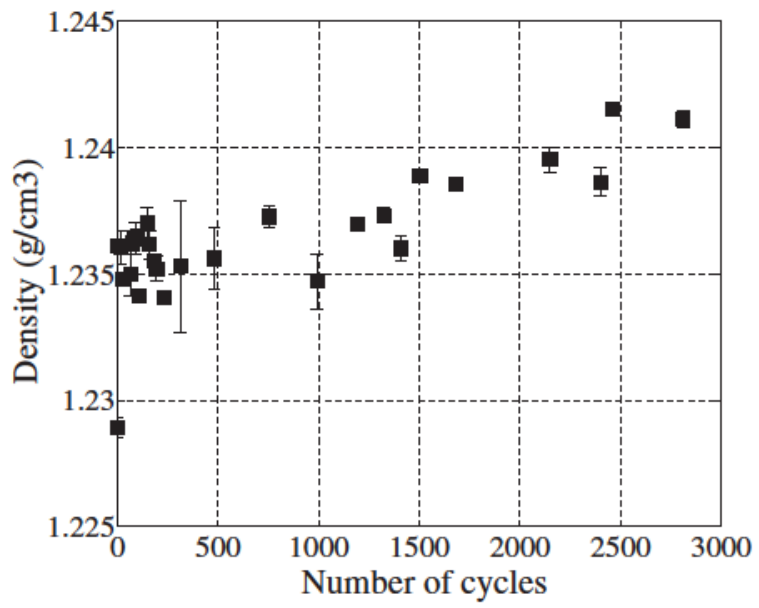

Fig. 13. Density in relation to the number of cycles.

epoxides [38,39] and polysulfones [40]. The first stage (few cycles) is dominated by sample "filling" with no or little swelling. In fact, despite the observed contraction (according to Eq. (4), the interaction coefficient $\chi$ would be negative), there is globally a volume increase (i.e. $0>\chi>V_{\mathrm{p}}^{-1}$ ) and thus swelling stress effects. During the second stage, the volume increase is almost equal to the volume of the (liquid) water absorbed. This stage stops after about 1000 cycles. In this second stage, we can estimate the coefficient of hydric expansion $(\beta)$, as depicted in Fig. 14. Hence, the second stage is dominated by swelling during which the polymer-water system approaches physical equilibrium.

With longer exposures (third stage), there is no more sample expansion, which is consistent with the hypothesis that all the supplementary water absorbed in this period is chemically bound to the polymer and does not participate in swelling. Hence, the third stage is dominated by chemical incorporation of water into the macromolecules with no swelling.

\section{Conclusion}

In this paper, we described in detail the aging behavior of an anhydride-cured epoxy resin under hygrothermal conditions. We reported important results on the sorption kinetics, the thermomechanical and hygroelastic behaviors, and the glass transition temperature. The different stages observed in the evolution of the

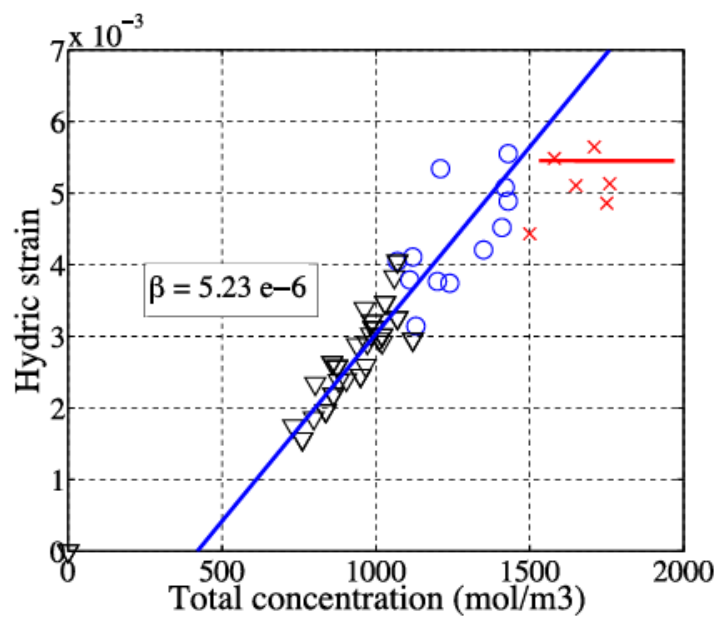

Fig. 14. The empirical relationship between the overall concentration of water and the hydric strain (volume change): estimation of the coefficient of hydric expansion $(\beta)$ during the swelling stage.

targeted quantities ( $m_{\mathrm{w}}, T_{\mathrm{g}}, E_{\mathrm{IIT}}$, etc.) indicate the complexity of the aging process. We hence proposed a degradation scenario that is consistent with our experimental observations.

Our line of reasoning is mainly based on dimensional measurements, particularly on the relationship between the volume change and the water uptake. We considered this result as the most relevant to describing the complex evolution of the polymer's properties during cyclic hygrothermal aging. Three main stages were identified:

- The "induction stage" during which the water that penetrates into the polymer has a small swelling effect. This results from the competition between water-induced swelling and the contraction effect characterized by the "interaction coefficient", $\chi$.

- The "swelling stage" during which the strain increases almost linearly with water concentration, with the coefficient of hydric expansion being: $\beta=5.23 \times 10^{-6} \mathrm{~m}^{3} / \mathrm{mol}$ (the water concentration being expressed in mole per $\mathrm{m}^{3}$ ).

- The "equilibrium stage" during which the supplementary mass uptake is due to water incorporation to macromolecules as a result of hydrolysis. This water does not contribute to swelling.

\section{References}

[1] Marouani S, Curtil L, Hamelin P. Ageing of carbon/epoxy and carbon/vinylester composites used in the reinforcement and/or the repair of civil engineering structures. Compos Part B Eng 2012;43(4):2020-30.

[2] Placette M, Fan X. A dual stage model of anomalous moisture diffusion and desorption in epoxy mold compounds. In: 12th Int. Conf, on thermal, mechanical and multiphysics simulation and experiments in microelectronics and microsystems 2011.

[3] Choi JW. Architecture of a knowledge based engineering system for weight and cost estimation for a composite airplane structures. Expert Syst Appl 2009;36(8):10828-36.

[4] Mouton S, Teissandier D, Sébastian P, Nadeau J. Manufacturing requirements in design: the RTM process in aeronautics. Compos Part A 2010;41(1):125-30.

[5] Hinrichsen J, Bautista C. The challenge of reducing both airframe weight and manufacturing cost. Air Space Eur 2001:3.

[6] Lafarie-Frenot M, Rouquié S, Ho N, Bellenger V. Comparison of damage development in c/epoxy laminates during isothermal ageing or thermal cycling. Comp Part A Appl Sci Manuf 2006;37:662-71.

[7] Mercier J, Bunsell A, Castaing P, Renard J. Characterisation and modelling of aging of composites. Comp Part A Appl Sci Manuf 2008;39(2):428-38.

[8] Oudad W, Madani K, Bouiadjra BB, Belhouari M, Cohendoz S, Touzain S, et al Effect of humidity absorption by the adhesive on the performances of bonded composite repairs in aircraft structures. Compos Part B Eng 2012;43:3419-24.

[9] Vauthier E, Abry J, Bailliez T, Chateauminois A. Interactions between hygrothermal ageing and fatigue damage in unidirectional glass/epoxy composites. Compos Sci Technol 1998;58(5):687-92. 
[10] Lafarie-Frenot M. Damage mechanisms induced by cyclic ply-stresses in carbone-epoxy laminates: environmental effects. Int J Fatigue 2006;28(10): $1202-16$.

[11] Lubineau G, Ladevèze P, Violeau D. Durability of CFRP laminates under thermomechanical loading: a micromechanics-based damage mesomodel. Compos Sci Technol 2006;66:983-92.

[12] Jelinski L, Dumais J, Cholli A, Ellis T, Karasz F. Nature of the water epoxy interaction. Macormol 1985;18:1091-5.

[13] Zhou J, Lucas J. Hygrothermal effects of epoxy resin. Part II: variations of glass transition temperature. Polymer 1999;40:5513-22.

[14] Bellenger V, Verdu J, Morel E Structure-properties relationships for densely cross-linked epoxide-amine systems based on epoxide or amine mixtures: Part 2: water absorption and diffusion. J Mater Sci 1989;24:63-8.

[15] Merdas I, Thominette F, Tcharkhtchi A, Verdu J. Factors governing water absorption by composite matrices. Compos Sci Technol 2002;62:487-92.

[16] Kelley F, Bueche F. Viscosity and glass temperature relations for polymerdiluent systems. J Polym Sci 1961;50:549-56.

[17] Fox T, Flory P. Second-order transition temperatures and related properties of polystyrene. I. Influence of molecular weight. J Appl Phys 1950;21:581-91.

[18] Hancock B, Zografi G. The relationship between the glass transition temperature and the water content of amorphous pharmaceutical solids. Pharma Res 1994;11:471-7.

[19] Popineau S, Rondeau-Mouro C, Sulpice-Gaillet C, Shanahan M. Free-bound water absorption in an epoxy adhesive. Polymer 2005;46:10733-40.

[20] Reid JD, Lawrence WH, Buck RP. Dielectric properties of an epoxy resin and its composite I. moisture effects on dipole relaxation. J Appl Polym Sci 1986;31 $1771-84$.

[21] Grave C, McEwan I, Pethrick RA. Influence of stoichiometric ratio on water absorption in epoxy resins. J Appl Polym Sci 1998;69:2369-76.

[22] McKague E, Reynolds J, Halkias J. Swelling and glass transition relations for epoxy matrix material in humid environments. J Appl Polym Sci 1978;22: $1643-54$.

[23] Cohn D, Marom G. A proposal for a coefficient of hygroelasticity. Polym Eng Sci 1978;18:1001-5.

[24] Gigliotti M, Jacquemin F, Vautrin A. Assessment of approximate models to evaluate transient and cyclical hygrothermoelastic stress in composite plates. Int J Solids Struct 2007;44:733-59.

[25] Derrien K, Gilormini P. The effect of applied stresses on the equilibrium moisture content in polymers. Scr Mater 2007;56:297-9.
[26] Tcharkhtchi A, Bronnec P, Verdu J. Water absorption characteristics of diglycidylether of butane diol-3,5-diethyl-2,4-diaminotoluene networks. Polymer 2000;41:5777-85.

[27] El Yagoubi J, Lubineau G, Roger F, Verdu J. A fully coupled diffusion-reaction scheme for moisture sorption-desorption in an anhydride-cured epoxy resin. Polymer 2012;1:11-5.

[28] Ashbee $\mathrm{K}$, Wyatt R. Water damage in glass fibre/resin composites. Proc Roy Soc A 1969;312:553-64.

[29] Gautier L, Mortaigne B, Bellenger V, Verdu J. Osmotic cracking nucleation in hygrothermal aged polyester matrix. Polymer 1999;41:2481-90.

[30] Lubineau G, Violeau D, Ladevèze P. Illustrations of a microdamage model for laminates under oxidizing thermal cycling. Compos SciTechnol 2009:69(1):3-9.

[31] Golike R, Lasoski S. Kinetics of hydrolysis of polyethylene terephthalate films. J Phys Chem 1960;64:895.

[32] Colin X, Verdu J. In: Song DB, editor. Thermooxidative and thermohydrolytic aging of organic composite matrices in resin composites: properties, production and application. New York: Nova Science Publishers; 2011. pp. 255-98.

[33] Colin X, Verdu J. In: Pochiraju KV, Tandon GP, Schoeppner GA, editors. Mechanisms and kinetics of organic matrix thermooxidation in long-term durability of polymeric matrix composites. New York: Springer; 2012. pp. 311-44.

[34] Le Huy H, Bellenger V, Verdu J, Paris M. Thermal oxidation of anhydride cured epoxies. 1-mechanistic aspects. Polym Degrad Stab 1992;35:77-86.

[35] Gigliotti M, Grandidier JC, Lafarie-Frenot MC. Assessment of chemomechanical couplings in polymer matrix materials exposed to thermooxidative environments at high temperatures and under tensile loadings. Mech Mater 2011:43:431-43.

[36] Bellenger V, Ganem M, Mortaigne B, Verdu J. Lifetime prediction in the hydrolytic ageing of polyesters. Polym Degrad Stab 1995;49:91-7.

[37] Rasoldier N, Colin X, Verdu J, Bocquet M, Olivier L, Chocinski-Arnault L, et al, Model systems for thermo-oxidised epoxy composite matrices. Compos Part A 2008;39:1522-9.

[38] Adamson M. Thermal expansion and swelling of cured epoxy resin used in graphite/epoxy composite materials. J Mater Sci 1980;15:1736-45.

[39] Perrin F, Nguyen M, Vernet J. Water transport in epoxy-aliphatic amine networks - influence of curing cycles. Eur Polym J 2009;45:1524-34.

[40] Marque G, Verdu J, Prunier V, Brown D. Molecular dynamic simulation of three polysulfones in dry and hydrated states. Polym Sci Part B Polym Phys 2010;48:2312-36. 